\title{
17 Degrees Celsius Body Temperature-Resuscitation Successful?
}

\author{
Sven Hungerer, Michael Ebenhoch, and Volker Bühren
}

\begin{abstract}
Hungerer, Sven, Michael Ebenhoch, and Volker Buhren. 17 degrees celsius body temperature-resuscitation successful? High Alt. Med. Biol. 11:369-374, 2010.-The resuscitation of patients with accidental profound hypothermia is challenging. A 17-year-old man got lost on the first of January, after a New Year's Eve party in the foothills of the Alps. After a search of four hours, he was found unconscious with fixed pupils, a Glasgow Coma Scale of three points, and a body temperature below $20^{\circ} \mathrm{Celsius}$. There were no signs for traumatic injuries. Initial electrocardiogram (ECG) showed no heart activity. Basic life support was begun by the mountain rescue service and continued by the medical helicopter team. The patient was transferred under continuous cardiac massage, airway management with intubation and intravenous line via external jugular vein by helicopter to the nearest hospital for analysis of serum potassium. Body temperature was $17^{\circ} \mathrm{C}$ measured by urinary bladder electronic thermometer. The serum potassium was $7.55 \mathrm{mmol} / \mathrm{L}$, therefore the patient was transferred by helicopter to the next cardiovascular center for rewarming with extracorporal circulation (ECC). Under the rewarming process with ECC, the heart activity restarted at 25deg; $\mathrm{C}$ with external defibrillation. The patient was rewarmed to $37.2^{\circ} \mathrm{C}$ after four hours of ECC. Cerebral CT scans after $24 \mathrm{~h}$ and $48 \mathrm{~h}$ revealed no significant hypoxia and after extubation the early rehabilitation process started. After six weeks, the patient regained the ability to walk and started to communicate on a basic level. After 54 days the patient presented signs of septic shock. After initial stabilization and CT diagnostic, a laparotomy was performed. The intraoperative finding was a total necrosis of the small bowel and colon. The patient died on the same day. Post mortem examination showed a necrotizing enterocolitis with transmural necrosis of the bowel. Survivors of uncontrolled profound hypothermia below $20^{\circ} \mathrm{C}$ core temperature are rare. The epicrisis is often prolonged by complications of different causes. The present case reports a necrotizing enterocolitis with a nonocclusive mesenteric ischemia (NOMI) as a medium-term complication of profound hypothermia.
\end{abstract}

Key Words: hypothermia; necrotizing enterocolitis; rewarming; coma

\section{Case Report}

A 17-YEAR-OLD healthy man attended a New Year's Eve party. He left the party in the morning hours around 5 a.m. with the intention of walking home approximately $20 \mathrm{~km}$ walking distance through the foothills of the Alps. The weather report for the night of New Year's Eve showed a minimum of $-12^{\circ} \mathrm{C}$ and during daytime a maximum of $-5^{\circ} \mathrm{C}$. The cloud ceiling was closed to the north and beginning to open up in the early morning hours on the mountain side to the south. The previous two days were snowfall with precipitation of $34 \mathrm{~mm}$ in the area, i.e., a snow cover of approximately $50 \mathrm{~cm}$.

In the morning at 7:24 a.m. the dispatch center of the police received an emergency call from the young man with the information that he lost orientation and was exhausted. An- other four calls were received until 8 a.m. but the information from the young man became more confused. The last log in of the mobile phone was documented at 8:15 a.m. (see Fig. 3).

The rescue helicopter Christoph 74 was alerted the first time at 8:24 a.m. for a search and rescue flight in the area where the young man was suspected of being. The police helicopters with infrared cameras were not able to take off because of the low visibility in the north. The area was roughly four square kilometers on a mountain side covered with trees. The rescue team searched for 28 minutes in vain until another rescue task had to be addressed. The search was continued with rescue dogs and the mountain rescue service on the ground. The cloud ceiling in the north rose about noon, and a police helicopter supported the search parties on the ground.

At 12:57 p.m. Christoph 74 was again alerted. The first information given was a young man found with hypothermia,

Trauma Center, Murnau, Germany. 


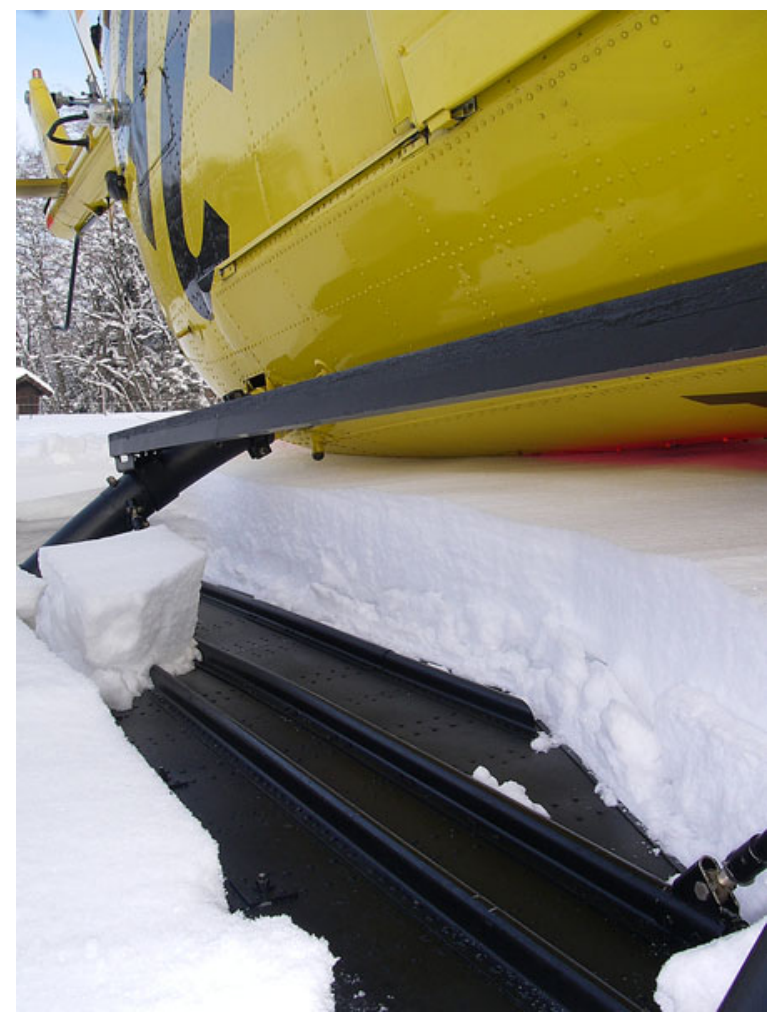

FIG. 1. Discovery site of the patient between the trees is marked with a red circle. The rescue helicopter landed in front of the hut approximately $150 \mathrm{~m}$ away.

location on the mountain between trees. A close landing was not possible, and a rescue winch required. The patient was found by the mountain rescue team unconscious, lying on his back, without vital signs. He was dressed in jeans and a fleece jacket. No signs of traumatic injuries were visible. The paramedics started the basic life support. After configuration of the helicopter for the winching operation and a flight time of ten minutes, the medical crew was winched to the position of the patient at 13:17 p.m. (Fig. 1).

On arrival of the medical team the patient had a Glasgow Coma Scale of three points, fixed pupils, the paddle electrocardiogram (ECG) showed asystole, body temperature was not measureable with epitympanic thermometer on board (minimum limit $20^{\circ} \mathrm{C}$ ). Basic life support was continued, airway managed with intubation and an intravenous (iv) line administered in the external jugular vein. The helicopter landed approximately $200 \mathrm{~m}$ away in an open area, and the patient was transferred under continuous basic life support to the helicopter (Fig. 2).

At 13:35 p.m. the helicopter took off in the direction of the nearest clinic with extracorporal circulation for rewarming. Due to the weather conditions, no German clinic in the north was available, therefore the team attempted to approach an Austrian hospital within 15 flight minutes. After three minutes in the air the Austrian hospital rejected the admission of the patient. Because of the unsafe weather conditions to the north and the continuing basic life support of the patient without any heart activity, the team decided to approach the nearest hospital for analysis of the serum potassium allowing an assessment of the prognosis for the patient (Schaller et al., 1990). The helicopter base was reached at 13:45 p.m., and the

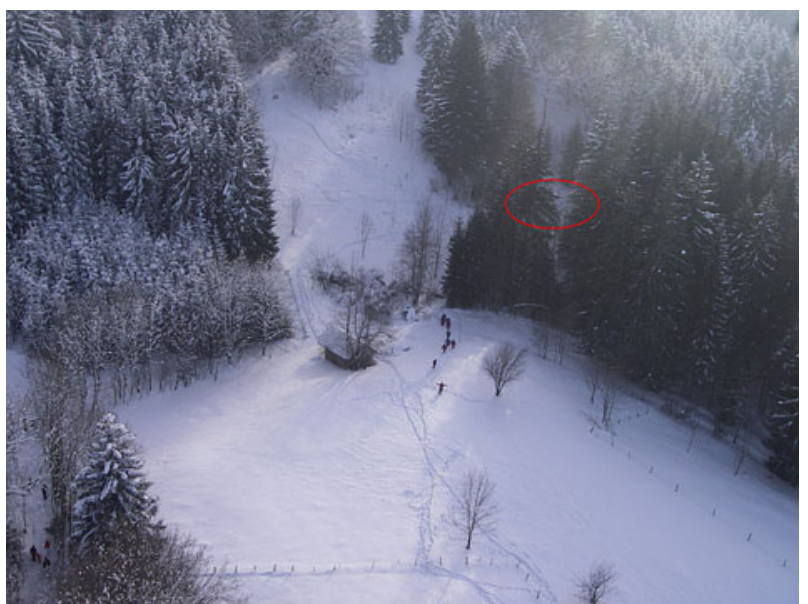

FIG. 2. Rescue situation on the ground during the transfer of the patient to the helicopter with the team of the mountain rescue group.

patient transferred to the shock room. The initial analysis of the arterial blood showed a $\mathrm{pH}$ of 6.88 , base excess of -18 $\mathrm{mmol} / \mathrm{L}$ and serum potassium of $7.55 \mathrm{mmol} / \mathrm{L}$, with a blood ethanol concentration of $1.41 \%$. The core temperature of the patient on admission was $17^{\circ} \mathrm{C}$ measured by electronic thermometer via the urinary bladder.

Since the serum potassium of $7.55 \mathrm{mmol} / \mathrm{L}$ was considered compatible with life, it was decided to continue the basic life support and the helicopter team again attempted to approach a hospital with cardiac surgery in the north despite the problematic weather conditions. At 14:34 p.m. the helicopter started again with the patient on board, and this time with two doctors to take turns doing CPR. The German Heart Center in Munich was reached at 14:58 p.m. and the patient was transferred directly to the operating room (Fig. 3).

The right femoral vessels were cannulated for the HLM, and the patient was rewarmed at a rate of $5^{\circ} \mathrm{C}$ per hour. At a body temperature of $25^{\circ} \mathrm{C}$ the patient was defibrillated once, the reentering rhythm was sinus rhythm, and he regained a sufficient circulation. ECC rewarming was terminated after four hours with a body temperature of $37.2^{\circ} \mathrm{C}$. During the rewarming the near infrared spectroscopy (NIRS) showed normal oxygen saturation of the brain circulation. The patient was transferred to the ICU receiving low doses of dopamine. The following day (day 1) was characterized by a rhabdomyolysis with a peak of $99700 \mathrm{U} / \mathrm{L}$ creatinine phosphokinase (CK), and dialysis was initiated.

The initial neurological examination on day 1 after resuscitation showed that the initial fixed pupils became reactive to light, no pathological reflexes were excitable, and the patient reacted to painful stimuli on all 4 extremities. The electroencephalogram (EEG) was mildly decelerated and the CCT scan showed no signs of brain swelling or hypoxia (Fig. 4).

The patient was transferred to our hospital on day 2. The patient was still on the respirator; , the cardiac situation was stable without support. The neurological situation without sedation improved slightly the following days. Enteral feeding started on day 3 via nasogastric tube. The cerebral MRI scan on day 9 showed signs of diffuse hypoxic brain damage. Nevertheless, the neurological situation improved, and weaning was finished on day 25. Renal function recovered, and dialysis finished the same day. Creatinine clearance recovered to 


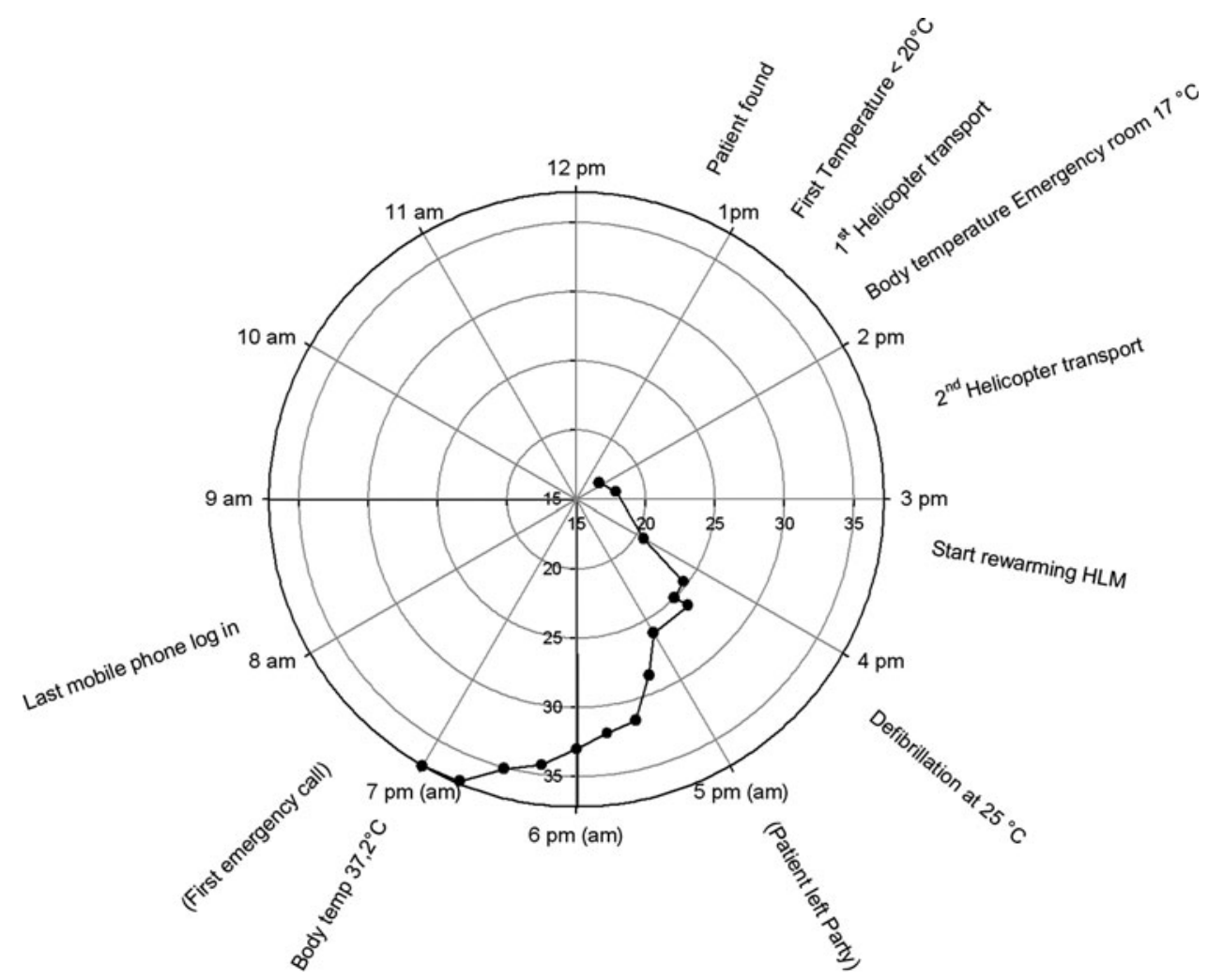

FIG. 3. Day 0 with chronological sequence of events and body temperature during rewarming process according to the time. The events in breaks are antemeridian where the clock time overlapped.

$30 \mathrm{~mL} / \mathrm{min}$. After the initial shock, the liver recovered as well, and a initial procalcitonin of $44 \mathrm{ng} / \mathrm{mL}$ declined without antibiotic treatment. On day 30 , the patient was discharged from the ICU and transferred to the neurological ward. On discharge from the ICU, the patient was able to move his extremities voluntarily and control his head. He followed easy commands. Swallowing training started, and drinking water was no problem. He was mobilized in a wheel chair. The neurological status improved further during the following weeks, and he gained the ability to walk using a walker. The patient's awareness improved as well as his verbal responses, and he reached the consciousness of an infant.

From day 48 the clinical situation was characterized by increasing times of agitation, and this was documented by the nurses. A lab from day 49 was without pathological findings. Because of unstableness of the deglutition, a percutaneous

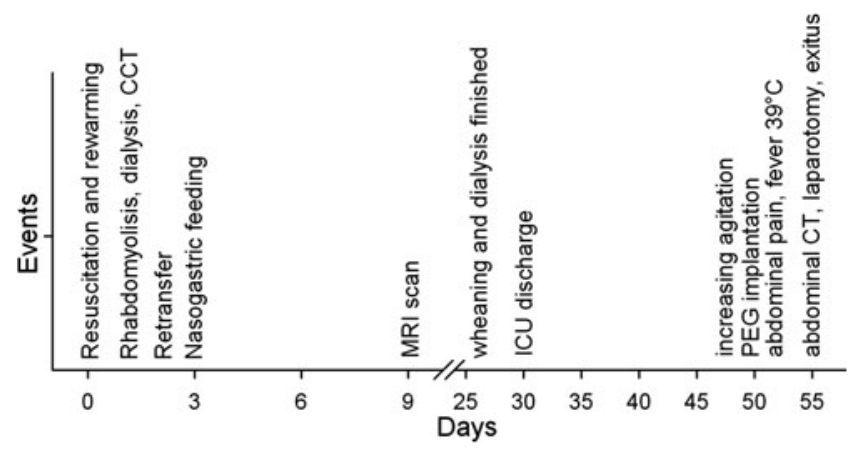

FIG. 4. Day 0 to Day 55 with chronological sequence of major events and clinical findings. endoscopic gastrostomy (PEG) was performed on day 50. The intraoperative gastroscopy was normal. After the PEG implantation, the patient had a fever peak to $39^{\circ} \mathrm{C}$ on day 51 but reached normal levels the following day.

On day 52 the patient complained for the first time about abdominal pain. Two days later, on day 54, the patient complained again about abdominal pain and refused to eat. During the following night the clinical situation worsened with vomiting and increasing abdominal pain. The consultant surgeon assessed the abdomen but saw no indication for further investigation. In the early morning hours the patient was transferred to ICU and an abdominal CT scan was initiated. The CT of the abdomen showed a massive intramural pneumatosis of the intestine and pneumatosis of the liver as well as mesenteric and portal venous gas and a pneumoperitoneum (Fig. 5). The mesenteric arteries were well contrasted, and no arterial occlusion or obstruction was found.

Emergency laparatomy was performed. The intraoperative finding was a total bowel ischemia from the Treitz ligament to the sigmoid. Intraoperative swab microbiology was positive for Staphylococcus aureus and Escherichia coli. The young man died the same day, 55 days after hypothermia.

Full autopsy was performed on day 57 by the Institute of Forensic Medicine of the University of Munich. The examination revealed no direct cause for the bowel ischemia, no irregularities of the aorta or mesenteric vessels. The implanted PEG was in the correct position in the stomach, and there was no hint for a leakage. The mucosa of the stomach and the small bowel presented a hemorrhagic necrosis. The bowel showed necrotic patches with highest intensity at the terminal ileum. A direct cause for the mesenteric ischemia was not detectable. 


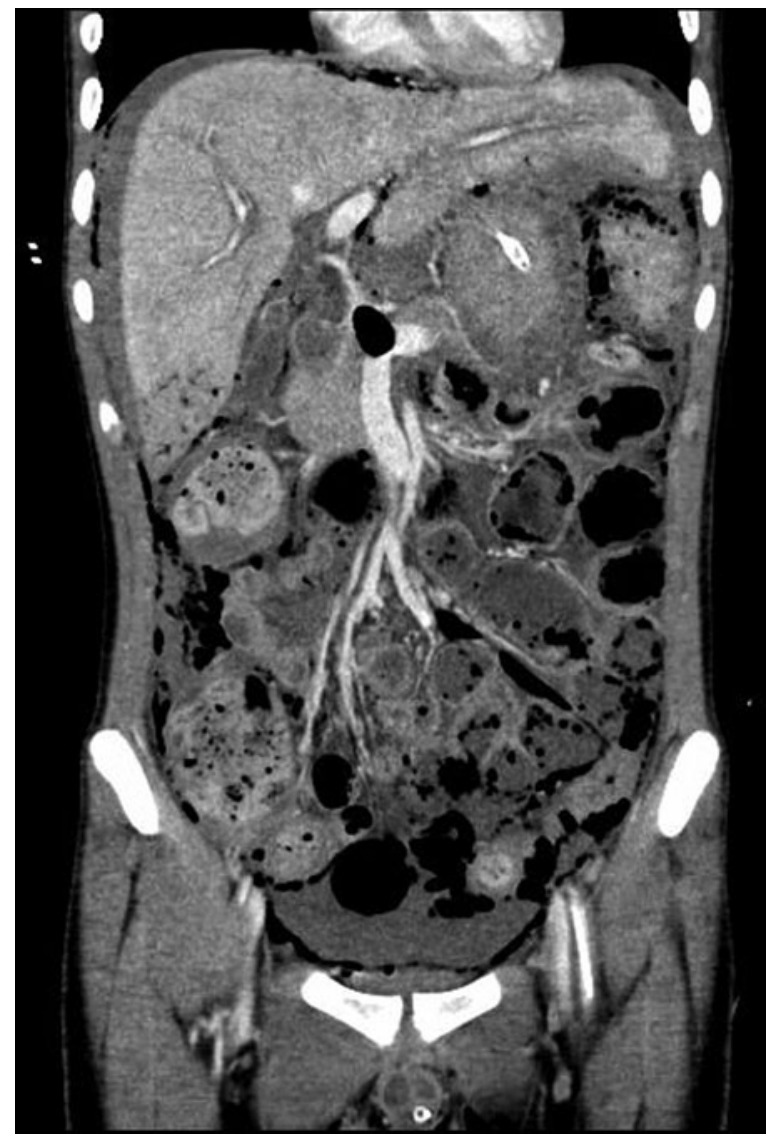

FIG. 5. CT scan on day 55 after clinical deterioration of the patient with abdominal pain and initial septic shock. The typical findings for mesenteric ischemia are the pneumatosis of the hepatic portal veins, the pneumatosis intestinalis and pneumoperitoneum.

\section{Discussion}

This tragic case report is remarkable because of several issues. First, this patient survived a severe hypothermia with cardiac arrest and a body core temperature of $17^{\circ} \mathrm{C}$ due to exposure to cold. The combination of inadequate thin clothing for the winter weather, alcohol consumption the preceding night, and exhaustion led to a fast cooling down of the young man's body temperature between the last contact around 8:00 a.m. and his discovery 5 hours later. This is equivalent to a cooling rate of at least $3.4^{\circ} \mathrm{C}$ per hour.

Second, the patient survived not only the several hours of cardiac arrest in deep hypothermia in the Alps. He also survived another 2.5 hours of CPR until he was connected to the HLM with a serum potassium of $7.55 \mathrm{mmol} / \mathrm{L}$ and a base excess of $--18 \mathrm{mmol} / \mathrm{L}$.

Third, despite a five-organ failure (brain, liver, kidneys, lungs, and coagulation), he survived and, despite a cardiac arrest time of unknown duration followed by cardiopulmonary resuscitation, he recovered neurologically.

Fourth, the devil never sleeps. The young man died due to a hemorrhagic necrotizing enteritis of the intestine with the intraoperative picture of a nonocclusive mesenteric ischemia (NOMI). Although it can not definitely be proved it must be speculated that the ischemia is a long-term sequel of severe hypothermia.

Several cases are documented with accidental profound hypothermia, i.e., body temperature below $28^{\circ} \mathrm{C}$ and successful resuscitation and rewarming. Only few reports exist of patients with a body temperature below $20^{\circ} \mathrm{C}$ (Table 1 ). The lowest body temperature documented with successful resuscitation was $13.7^{\circ} \mathrm{C}$ (Gilbert et al., 2000). This case was a 29 -year-old woman who got wedged in a waterfall gully and was continuously cooled by icy water. The young woman stopped moving after 40 minutes and was freed after nearly 90 minutes with a body temperature of $13.7^{\circ} \mathrm{C}$. The rewarming process was performed approximately after 120 minutes of CPR. The parallels between this patient and our patient are the cooling of the body temperature under normoxic conditions. Both patients were resuscitated and arterial blood samples showed an excessive metabolic acidosis. The rewarming with ECC was successful in both patients, and an initial sufficient cardiac function restored. The postischemic complications were comparable in both patients with multiple organ failure (MOF). The occurrence of transitory hemorrhagic diathesis, atrophic gastritis and ischemic colitis was reported in the young woman. The differences

Table 1. Patients with Body Temperature Below $20^{\circ} \mathrm{C}$

\begin{tabular}{|c|c|c|c|c|c|c|}
\hline Reference & $\begin{array}{l}\text { Age } \\
\text { and sex }\end{array}$ & $\begin{array}{c}\text { Body } \\
\text { temperature }\left[{ }^{\circ} \mathrm{C}\right]\end{array}$ & Mechanism & $\begin{array}{l}\text { Resuscitation } \\
\text { time [min] }\end{array}$ & $\begin{array}{l}\text { Rewarming } \\
\text { method }\end{array}$ & Complications \\
\hline [2] & $29 \mathrm{y} \mathrm{f}$ & $13.7^{\circ} \mathrm{C}$ & Crevasse/water & 120 & $\mathrm{ECC}$ & $\begin{array}{l}\text { Pulmonary edema, renal failure, } \\
\text { Hemorrhagic diathesis, atrophic } \\
\text { gastritis, ischemic colitis }\end{array}$ \\
\hline [30] & $42 \mathrm{y} \mathrm{m}$ & $19^{\circ} \mathrm{C}$ & Avalanche & 160 & ECC & Pulmonary edema, renal failure \\
\hline \multirow[t]{3}{*}{ [3] } & unknown & $17.5^{\circ} \mathrm{C}$ & Fall into crevasse & 156 & ECC & Pulmonary edema \\
\hline & unknown & $19.0^{\circ} \mathrm{C}$ & Fall into crevasse & 240 & $\mathrm{ECC}$ & \\
\hline & unknown & $20.0^{\circ} \mathrm{C}$ & Fall into crevasse & 280 & & \\
\hline [31] & $6 y \mathrm{~m}$ & $16.4^{\circ} \mathrm{C}$ & Water immersion & 95 & ECC & Rhabdomyolyisis, PNP \\
\hline [14] & $2 \mathrm{y} \mathrm{m}$ & $19.0^{\circ} \mathrm{C}$ & Water submersion & 180 & ECC & $\begin{array}{l}\text { Pulmonary edema, ileum } \\
\text { perforation }\end{array}$ \\
\hline [15] & $58 \mathrm{y} \mathrm{f}$ & $19.8^{\circ} \mathrm{C}$ & Freezing & unknown & ECC & $\begin{array}{l}\text { Pancreatitis, pulmonary edema, } \\
\text { peritonitis }\end{array}$ \\
\hline \multirow[t]{4}{*}{ [4] } & $53 \mathrm{y} \mathrm{f}$ & $19.6^{\circ} \mathrm{C}$ & Avalanche & unknown & $\mathrm{ECC}$ & not specified \\
\hline & $42 \mathrm{y} \mathrm{m}$ & $20^{\circ} \mathrm{C}$ & Fall into crevasse & unknown & & \\
\hline & 13 y m & $17.1^{\circ} \mathrm{C}$ & Fall into crevasse & unknown & & \\
\hline & 17 y m & $20^{\circ} \mathrm{C}$ & $\begin{array}{l}\text { Exposure } \\
\quad \text { (suicide attempt) }\end{array}$ & unknown & & \\
\hline
\end{tabular}


are the more rapid cooling process of the young woman by cold water immersion leading to severe hypothermia in only 40 minutes, the normal serum potassium on admission, and it must be assumed, that the ischemia reperfusion time was much shorter in the young woman.

Different prognostic factors were identified for patients with severe hypothermia. The mechanisms leading to profound hypothermia were in most reported cases submersion, immersion, or avalanche accidents with snow burying (Table 1). A fast cooling process without hypoxia or asphyxia is the optimum for the prognosis (Locher et al., 1991; Walpoth et al, 1997). Oxygen consumption is reduced to approximately $24 \%$ of normal at a core temperature of $20^{\circ} \mathrm{C}$ and each degree Celsius drop of the body temperature reduces oxygen consumption by approximately 6\% (Wong, 1983 .

The present case is particular for the mechanism of the profound hypothermia. The young man was only exposed to the cold environment. The induction of hypothermia might have been accelerated by the preceding alcohol consumption and exhaustion of the patient. This suggests a cooling rate of $3-4^{\circ} \mathrm{C} /$ hour and is as rapid as found in avalanche victims (Oberhammer et al., 2008).

The rescue of asystolic hypothermic patients is often associated with long CPR times by force of the circumstances, i.e., search of the missing after avalanche burying, drowning, etc. and the time needed for transport to a facility with ECC. Not only the body temperature at discovery of the patient is a prognostic factor for the outcome, but also the duration of CPR until ECC is initiated. However CPR times of two to four hours are not uncommon (Locher et al., 1991) and even durations of 6.5 hours have been reported to be successful (Lexow, 1991). Therefore, the duration of CPR is a weak factor and, more significant, is the serum potassium level in asystolic patients.

Locher et al. (1991) reported a serum potassium $>7$ $\mathrm{mmoL} / \mathrm{L}$ as a prognostic unfavorable factor. Schaller et al. (1990) draws the line for potassium levels above $10 \mathrm{mmoL} / \mathrm{L}$. It was no question for the medical team to continue CPR in the present case with a serum potassium of $7.55 \mathrm{mmoL} / \mathrm{L}$, although it was an indicator for a hypoxic damage.

With almost all successful resuscitations after profound hypothermia, the rewarming was performed with ECC (Table 1). The first descriptions of rewarming of accidental hypothermia with extracorporeal blood warming were reported in 1967 (Davies et al., 1967; Kugelberg et al., 1967). Other methods for rewarming have been reported, such as pleural lavage (Kjaergard and Bach, 2006), peritoneal dialysis (Jessen and Hagelsten, 1978), and intermittent hemodialysis (Sultan et al., 2009). The impediment to these methods is the need for a residual circulatory function. In cardiac arrest and under CPR conditions, these rewarming methods are inapplicable. ECC is the present gold standard for patients with profound hypothermia (Walpoth et al., 1997; Oberhammer et al., 2008; Danzl and Pozos, 1994).

Complications and MOF are commonly seen after resuscitation from profound hypothermia. Abdominal complications are atrophic gastritis and ischemic colitis (Gilbert et al., 2000), ileum perforation (Bolte et al., 1988), or peritonitis (Vionnet et al., 2004). In the present case the lethal complication was a hemorrhagic necrotizing enteritis involving the small bowel and the colon. The intraoperative picture was nonocclusive bowel ischemia in accordance with the preoperative contrastenhanced CT that revealed no arterial perfusion deficits. The pathological finding after post mortem examination was a hemorrhagic necrotizing gastroenterocolitis. The necrotizing enterocolitis is usually found in preterm infants and associated with a reduced immunological competence of the host in combination with an intestinal barrier disruption (Anand et al., 2007). Risk factors in the development of a necrotizing enterocolitis are premature immune-competence and aggressive administration of enteral feeds and hyperosmolar formulas. The necrotizing enterocolitis leads to an intestinal ischemia. Necrotizing enteritis in adults is mostly associated with immunosuppression (Cunningham et al., 2005) or infections (Sobel et al., 2005; Andres et al., 2007). The literature is inconclusive whether necrotizing enterocolitis in adults is part of the development of a nonocclusive mesenteric ischemia comparable to preterm infants.

The only change in the therapy regimen of the young man was the implantation of a PEG five days prior to his death because of local ulceration of the nose caused by the nasogastric tube. The postmortem examination revealed no leakage or local strangulations of the bowel nor mesentery. The incidence of small bowel ischemia after jejunal tube feeding in surgical patients is estimated from 1\%-3.5\% (Spalding et al., 2009; Gaddy et al., 1986). In a systematic review of the literature, Melis et al. (2006) found no correlation to comorbidities such as atherosclerosis, diabetes, etc. In none of these clinical cases was an occlusion of the mesenteric vessels apparent. The clinical symptoms are unspecific and therefore the mortality rate is very high at $41 \%-100 \%$ of the cases. The pathophysiology remains unclear and a multifactor genesis is likely, such as hyperosmolarity of feeding and intestinal bacterial overgrowth.

Nevertheless, it seems unlikely that the tube feeding is the direct cause for the deterioration of the clinical course in the present case, since the enteral feeding started 48 days before. The only problems associated with the nasogastric occurred the several times the patient pulled out the tube. On the other hand, since the young man had the mental status of an infant, he might have limited an enteral distress by removing the gastric tube.

In the present case the intraoperative swab microbiology from the laparotomy was positive not only for Escherichia coli, as expected, but also for Staphylococcus aureus. The same bacteria was found 36 days before in the endotracheal aspirate of the patient. The combination of Staph. aureus and E. coli with same resistance antibiogram was found $33,29,26$, and 25 days in the endotracheal aspirate before the patient died. As inflammatory parameters increased he was treated with antibiotics for 10 days first with the chinolone antibiotic ciprofloxacin and later with the carbapenem antibiotic meropenem. After the treatment with the antibiotics, the white blood cell count and C-reactive protein were back in normal range. The further clinical course gave no suspicion for an active infection. There are only few reports in the literature for Staphylococcus aureus associated peritonitis after PEG implantation. The rate of peritonitis after PEG implantation is up to $2.3 \%$ (Potack and Chokhavatia, 2008). The common sequel of events is a peristomal infection and in some of these cases the development of staphylococcal-associated peritonitis. The risk factor for the development of a PEG-related infection is the oropharyngeal colonization (Faias et al., 2006), which would fit in the present case. The association between staphylococcus-induced peritonitis and necrotizing enterocolitis in adults has been described once (Lieverse et al., 2001). In peritoneal dialysis the coincidence of staphylococcusassociated peritonitis and nonocclusive mesenteric ischemia is more common (Szeto et al., 2007; Archodovassilis et al., 2007. 
Another possible mechanism is a Staphylococcus aureusinduced enterocolitis leading to necrosis of the bowel (Thakkar and Agrawal, 2010; Lin et al., 2009). Although it seems likely that Staphylococcus aureus contributed to the fatal events, the exact mechanisms remain unclear since no stool culture was analyzed nor toxin analysis was performed.

A consolidated view indicates that several factors coincided, leading to the terminal complication of a necrotizing gastroenteritis with subsequent nonocclusive mesenteric ischemia. There is no doubt that without the profound hypothermia and MOF after resuscitation the final complication would not have occurred. The trigger for the necrotizing gastroenteritis could have been a clinical unapparent infection, the enteral tube feeding, a Staphylococcus aureus-induced peritonitis, or the ischemia-reperfusion injury of the gut after the resuscitation itself. When treating such patients one must be sensitive to unimpressive warning signals in the clinical course in order to get a chance to act at a reversible stage of the complication.

\section{References}

Althaus U., Aeberhard P., Schupbach P., Nachbur B.H., Muhlemann W. (1982). Management of profound accidental hypothermia with cardiorespiratory arrest. Ann Surg 195:492-495.

Anand R.J., Leaphart C.L., Mollen K.P., Hackam D.J. (2007). The role of the intestinal barrier in the pathogenesis of necrotizing enterocolitis. Shock 27:124-133.

Andres L.A., Ford R.D., Wilcox R.M. (2007). Necrotizing colitis caused by systemic aspergillosis in a burn patient. J Burn Care Res 28:918-921.

Antretter H., Dapunt O.E., Mueller L.C. (1994). Survival after prolonged hypothermia. N Engl J Med 330:219.

Archodovassilis F., Lagoudiannakis E.E., Tsekouras D.K., Vlachos K., Albanopoulos K., Fillis K., Manouras A., Bramis J. (2007). Nonocclusive mesenteric ischemia: A lethal complication in peritoneal dialysis patients. Perit Dial Int 27:136-141.

Bolte R.G., Black P.G., Bowers R.S., Thorne J.K., Corneli H.M. (1988). The use of extracorporeal rewarming in a child submerged for 66 minutes. JAMA 260:377-379.

Cunningham S.C., Fakhry K., Bass B.L., Napolitano L.M. (2005). Neutropenic enterocolitis in adults: Case series and review of the literature. Dig Dis Sci 50:215-220.

Danzl D.F., Pozos R.S. (1994). Accidental hypothermia. N Engl J Med 331:1756-1760.

Davies D.M., Millar E.J., Miller I.A. (1967). Accidental hypothermia treated by extracorporeal blood warming. Lancet 1:1036-1037.

Faias S., Cravo M., Claro I., Lage P., Nobre-Leitao C. (2006). High rate of percutaneous endoscopic gastrostomy site infections due to oropharyngeal colonization. Dig Dis Sci 51:2384-2388.

Fremont-Smith M., Fischer M., Killgore G., Britz P.H., MacDonald C. (2005). Necrotizing enterocolitis associated with clostridium perfringens type $\mathrm{A}$ in previously healthy North American adults. J Am Coll Surg 201:48-56.

Gaddy M.C., Max M.H., Schwab C.W., Kauder D. (1986). Small bowel ischemia: A consequence of feeding jejunostomy? South Med J 79:180-182.

Gilbert M., Busund R., Skagseth A., Nilsen P.A., Solbo J.P. (2000). Resuscitation from accidental hypothermia of 13.7 degrees C with circulatory arrest. Lancet 355:375-376.

Jessen K., Hagelsten J.O. (1978). Peritoneal dialysis in the treatment of profound accidental hypothermia. Aviat Space Environ Med 49:426-429.

Kjaergaard B., Bach P. (2006). Warming of patients with accidental hypothermia using warm water pleural lavage. Resuscitation 68:203-207.
Kugelberg J., Schüller H., Berg B., Kallum B. (1967). Treatment of accidental hypothermia. Scand J Thorac Cardiovasc Surg 1: 142-146.

Lexow K. (1991). Severe accidental hypothermia: survival after 6 hours 30 minutes of cardiopulmonary resuscitation. Arctic Med Res 50 Suppl 6:112-114.

Lieverse R.J., van H.J., Fedder G., Bakker J., Heilmann F.G. (2001). Necrotizing enterocolitis in a married couple due to a staphylococcal toxin. Eur J Gastroenterol Hepatol 13:595-597.

Lin Z., Kotler D.P., Schlievert P.M., Sordillo E.M. (2009). Staphylococcal enterocolitis: Forgotten but not gone? Dig Dis Sci. 55:1200-1207.

Locher T., Walpoth B., Pfluger D., Althaus U. (1991). [Accidental hypothermia in Switzerland (1980-1987)—case reports and prognostic factors]. Schweiz Med Wochenschr 121:1020-1028.

Melis M., Fichera A., Ferguson M.K. (2006). Bowel necrosis associated with early jejunal tube feeding: A complication of postoperative enteral nutrition. Arch Surg 141:701704.

Oberhammer R., Beikircher W., Hormann C., Lorenz I., Pycha R., Adler-Kastner L., Brugger H. (2008). Full recovery of an avalanche victim with profound hypothermia and prolonged cardiac arrest treated by extracorporeal re-warming. Resuscitation 76:474-480.

Potack J.Z., Chokhavatia S. (2008). Complications of and controversies associated with percutaneous endoscopic gastrostomy: Report of a case and literature review. Medscape J Med 10:142.

Schaller M.D., Fischer A.P., Perret C.H. (1990). Hyperkalemia. A prognostic factor during acute severe hypothermia. JAMA 264:1842-1845.

Sobel J., Mixter C.G., Kolhe P., Gupta A., Guarner J., Zaki S., Hoffman N.A., Songer J.G., Fremont-Smith M., Fischer M., Killgore G., Britz P.H., MacDonald C. (2005). Necrotizing enterocolitis associated with clostridium perfringens type A in previously healthy North American adults. J Am Coll Surg. 201:48-56.

Spalding D.R., Behranwala K.A., Straker P., Thompson J.N., Williamson R.C. (2009). Non-occlusive small bowel necrosis in association with feeding jejunostomy after elective upper gastrointestinal surgery. Ann R Coll Surg Engl 91:477-482.

Sultan N., Theakston K.D., Butler R., Suri R.S. (2009). Treatment of severe accidental hypothermia with intermittent hemodialysis. CJEM 11:174-177.

Szeto C.C., Chow K.M., Kwan B.C., Law M.C., Chung K.Y., Yu S., Leung C.B., Li P.K. (2007). Staphylococcus aureus peritonitis complicates peritoneal dialysis: review of 245 consecutive cases. Clin J Am Soc Nephrol 2:245-251.

Thakkar S., Agrawal R. (2010). A case of Staphylococcus aureus enterocolitis: A rare entity. Gastroent Hepat 6:115-119.

Vionnet M., Mueller X., von Segesser L.K. (2004). Unusual complications after rewarming for deep accidental hypothermia. Thorac Cardiovasc Surg 52:185-186.

Walpoth B.H., Walpoth-Aslan B.N., Mattle H.P., Radanov B.P., Schroth G., Schaeffler L., Fischer A.P., von S.L., Althaus U. (1997). Outcome of survivors of accidental deep hypothermia and circulatory arrest treated with extracorporeal blood warming. N Engl J Med 337:1500-1505.

Wong K.C. (1983). Physiology and pharmacology of hypothermia. West J Med 138:227-232.

Address correspondence to: Sven Hungerer, $M D$

Trauma Center Murnau Prof. Küntscherstr. 8 82418 Murnau Germany

E-mail: shungerer@bgu-murnau.de 